\title{
Genetic effects from an Afrikaner, Bonsmara, and Nguni three-breed diallel and top- crosses of Angus and Simmental sires
}

\author{
G.M. Pyoos ${ }^{1,2 \#, ~ M . M . ~ S c h o l t z ~}{ }^{1,2}$, M.D. MacNeil ${ }^{1,2,4}$, A. Theunissen ${ }^{3}$ \& F.W.C. Neser ${ }^{2}$ \\ ${ }^{1}$ Agricultural Research Council, Animal Production Institute, Irene, South Africa \\ ${ }^{2}$ University of the Free State, Department of Animal, Wildlife and Grassland Sciences, Bloemfontein, South Africa \\ ${ }^{3}$ Northern Cape Department of Agricultural, Land Reform and Rural Development, Jan Kempdorp, South Africa \\ ${ }^{4}$ Delta G, Miles City, MT 59301, USA
}

(Received 19 December 2019; Accepted 13 May 2019; First published online 31 May 2020)

\begin{abstract}
Copyright resides with the authors in terms of the Creative Commons Attribution 4.0 South African Licence.
See: http://creativecommons.org/licenses/by/4.0/za

Condition of use: The user may copy, distribute, transmit and adapt the work, but must recognise the authors and the South African Journal of Animal Science.
\end{abstract}

\begin{abstract}
Individual and maternal breed additive effects and heterosis exist for most economically important traits in cattle. Crossbreeding may therefore be valuable for emerging and commercial beef farmers in improving the productivity of their herds. Calves were produced by mating Afrikaner, Bonsmara and Nguni cows to Afrikaner, Bonsmara, Nguni, Angus and Simmental bulls. The cows used were from Vaalharts Research Station or were purchased from other herds. Data were collected over three years. Individual and maternal additive effects and individual heterosis were estimated simultaneously as continuous linear variates. The estimated genetic effects were then used to predict production levels that may be achieved through implementation of top-cross, two-breed rotation, and terminal sire crossbreeding systems. The individual estimates of the genetic effects were relatively small and in most cases were not different from zero, with the exception of the maternal additive effects of Nguni on preweaning traits and their individual additive effect on cow weight, which were less than those of Bonsmara. However, the alternative crossbreeding systems differed across traits. The straight-bred breeding system was least efficient, followed by the crisscross system $(+2 \%)$ and the terminal sire system that utilized Simmental $(+4 \%)$, with the terminal sire system utilizing Angus being on average most efficient $(+8 \%)$. The inter-generational genetic differences in cow weight that resulted from the use of different breeds of sire increased its standard deviation by 5 to $6 \%$ in rotational crossing. Despite the relatively small magnitude of the genetic effects, advantages of crossbreeding systems became evident.
\end{abstract}

Keywords: breed additive, crossbreeding, heterosis, post-weaning, pre-weaning

\#Corresponding author: pyoosg@arc.agric.za

\section{Introduction}

Individual and maternal breed additive effects and heterosis exist for most economically important traits in cattle and result in observable differences among breeds (Cunningham, 1987; Gregory et al., 1991). Increasing the efficiency of beef production depends on effective exploitation of these genetic differences because they could lead to economic differences that may be realized through crossbreeding. This may be carried out through selection of breed combinations that express complementarity and heterosis, and facilitate adaptation to adverse conditions and limited resources (Long, 1980). Thus, the first step in predicting the outcome from a crossbreeding system is to understand the genetic effects of the breeds that are available (Dickerson, 1969; Dillard et al., 1980; Robison et al., 1981). Then the objective of an effective crossbreeding system is to optimize the systematic use of these effects (Kinghorn, 1980, 1982; MacNeil, 1987).

It is commonly recognized that crossbred animals may have greater merit for reproduction, growth and end product traits (e.g., Spangler, 2007). Crossbred Bos taurus - Bos indicus females have been used extensively in subtropical and tropical regions of the world owing to their exceptional productivity and longevity compared with crossbred Bos taurus females in these environments (Arce, 2006). Similarly, taurine-indicine heterosis effects were found to be significant for estimates of growth curve parameters, total milk yield, calf weaning weight, predicted energy intake by cows and cow efficiency, and greater than those 
for taurine breed crosses (Mendonça et al., 2019). However, an even greater benefit of heterosis was observed expressed in crosses of breeds adapted to different environments (Bunning et al., 2019). Because the Sanga cattle breeds are likely to be composites between Bos taurus and Bos indicus (Hanotte et al., 2002; Makina et al., 2016), this may in part explain their adaption to the South African environment. It has been commonly recommended that Sanga breeds (such as the Nguni and Afrikaner) should be used as dam lines (Epstein, 1971; Frisch, 1973; Ramsay, 1985).

Furthermore, exotic breeds such as Angus and Simmentaler may play significant roles as sire lines to increase weights of calves that are produced from indigenous breeds of dam (MacNeil \& Matjuda, 2007; Theunissen et al., 2013). Thus, crossbreeding may be valuable to emerging and commercial beef farmers in order to improve the productivity of their herds and economic returns from them.

Heterosis has significant influences through its favourable effects on virtually all economically important traits of beef cattle and thus may collectively improve productivity (Cartwright et al., 1964; Gregory et al., 1965; Hedrick et al., 1970; Willham, 1974). Additionally, based on their experiments with plants, Griffing \& Zsiros (1971) proposed that the level of heterosis expressed might depend on the environment. This observation is important because it has been suggested that an ideal breeding system should be well matched to the production environment (Haldane, 1946; Long, 1980).

Estimates of breed additive effects and heterosis can be combined into multi-breed genetic prediction models to predict phenotypic performance (MacNeil et al., 1987; Cardoso \& Templeman, 2004; Pollak, 2006). Most frequently (e.g. Amen et al., 2007; Eriksson et al., 2020), heterosis, breed direct, and breed maternal effects have been estimated from linear functions of breed group means and have inference only to the specific crosses that were evaluated. However, these effects can be more efficiently estimated by multiple regression, which allows for prediction of untested breed combinations (MacNeil et al., 1988). Thus, the first objective of this study was to estimate individual and maternal breed additive effects and direct heterosis effects on birth weight, preweaning average daily gain, weaning age, 205-day weight, and cow weight at weaning. The second objective was to use the estimated genetic effects to predict production levels that may be achieved through implementation of top-cross, two-breed rotation, and terminal sire crossbreeding systems of the Afrikaner (AF), Bonsmara (BN), and Nguni (NG) dam lines mated with AF, BN, NG, Angus (AN), and Simmentaler (SM) sire lines.

\section{Material and Methods}

All the data were collected in terms of the guidelines of the National Beef Cattle Improvement Scheme as mandated by government under the Animal Improvement Act 83 of 1989. Ethical clearance was granted by the ARC-AP, number: APIEC18/16. The experimental data originated from Vaalharts Research Station in the Northern Cape of South Africa, which is situated at $27^{\circ} 57^{\prime} 19^{\prime \prime} \mathrm{S}$ and $24^{\circ} 50^{\prime} 41^{\prime \prime}$ E with mixed Tarchonanthus veld, Veld type No. 16b (Acocks, 1988; Herman, 2002). It has an estimated average carrying capacity of $10 \mathrm{ha} / \mathrm{LSU}$. The climate is classified as semi-arid and characterized by hot summers, with average maximum temperature of $32{ }^{\circ} \mathrm{C}$ being experienced during December and January and cold winters with the lowest monthly average temperature of $-0.5^{\circ} \mathrm{C}$ in July. Average annual rainfall is approximately 440 $\mathrm{mm}$.

A total of 576 cows were used in this study. A BN herd has been kept at Vaalharts since 1986, with BN cows from the Wesselsvlei line being introduced there in 2008. An NG herd was established at Vaalharts between 2007 and 2008. The AF herd was acquired specifically for this research. The purchased AF and NG cows originated from herds in Central Free State $(N=59)$, southern Free State $(N=3)$, Northern Cape $(N=$ 21), North West $(N=11)$, Eastern Cape $(N=5)$, Limpopo $(N=30)$, Mpumalanga $(N=9)$, and Namibia $(N=$ 8).

In the first year of the three years of data collection (2014), cows of each breed were stratified by age, weight and estimated breeding values. They were then assigned to mating groups within strata to avoid the possibility of uneven genetic merit of cows mated to any breed of bull. With the exception that some of the AF cows were pregnant when they were purchased, each bull was used across the three breeds of dam and there was connectedness of sires across years. The mating season was in summer, from 1 December until 28 February. At least two bulls of each breed were assigned to a specific mating group. Thus, the AF, BN and NG cows produced calves sired by AF, BN, NG, AN and SM bulls. In year 1, single sire mating was used, whereas in years 2 and 3 multiple sire mating was used and paternal parentage is therefore unknown. The fifteen breed groups and numbers of calves produced are shown in Table 1. 
Table 1 Crossbreeding plan indicating total number of calves that were weaned in each of the mating groups for all three years (2014-2016)

\begin{tabular}{lccccc}
\hline \multirow{2}{*}{ Breed of dam } & \multicolumn{5}{c}{ Breed of sire } \\
\cline { 2 - 6 } & Afrikaner & Bonsmara & Nguni & Angus & Simmental \\
\hline \multirow{2}{*}{ Afrikaner } & 33 & 12 & 12 & 9 & 6 \\
Bonsmara & 21 & 78 & 39 & 33 & 30 \\
Nguni & 54 & 54 & 117 & 39 & 42 \\
\hline
\end{tabular}

Breeding occurred on natural veld pastures that contained bulls from one breed of sire. After the breeding season, all cows were kept in one herd until calving. As the cows calved, they were moved to another paddock with the other cow-calf pairs. All calves were raised by their dams from birth through weaning at approximately 205 days old. Birth dates were recorded and calves were weighed within 48 hours of birth. Each year, all calves were weaned and weighed on the same day.

Cows were culled voluntarily when they did not meet minimum breed standards for fertility. Thus, 48 cows were replaced with two-year-old heifers of the same breed from animals that were produced in this project or were purchased through the breed society or at auctions that were held under the auspices of the society. Involuntarily culled cows (death, injury, old age, etc.) were replaced in a similar way.

Purebred bulls were purchased on local sales that were held under the auspices of their breed societies. Thus, all bulls were deemed to be of acceptable genetic merit by these breed societies and had official breeding values for the growth traits. Averages of the EBV for birth weight, 205-day weight and cow weight of bulls that were utilized in the study along with the comparable breed averages are presented in Table 2. The number of bulls sampled from each breed of sire was quite small and thus caution is warranted in interpreting the breed-specific results that are presented below. However, the average EBV of the bulls used in this project did not deviate greatly from their breed averages.

Table 2 Average estimated breeding values for sires used in the crossbreeding project at Vaalharts research station compared with their breed averages ${ }^{1}$

\begin{tabular}{|c|c|c|c|c|c|c|}
\hline \multirow{2}{*}{ Breed of sire } & & \multicolumn{2}{|c|}{ Birth weight, kg } & \multicolumn{2}{|c|}{ 205-day weaning weight, kg } & \multirow{2}{*}{$\begin{array}{c}\text { Cow weight, } \mathrm{kg} \\
\text { direct }\end{array}$} \\
\hline & & direct & maternal & direct & maternal & \\
\hline \multirow{2}{*}{ Afrikaner $(\mathrm{N}=7)$} & $\bar{x}$ & -0.15 & +0.30 & +4.93 & +4.17 & -1.1 \\
\hline & $\mu$ & -0.02 & +0.30 & +4.67 & +4.30 & -1.1 \\
\hline \multirow{2}{*}{ Bonsmara $(\mathrm{N}=3)$} & $\bar{x}$ & +0.13 & +0.06 & +11.70 & +4.00 & +10.0 \\
\hline & $\mu$ & +0.38 & +0.04 & +7.60 & +9.60 & +3.7 \\
\hline \multirow{2}{*}{ Nguni $(\mathrm{N}=3)$} & $\bar{x}$ & +0.12 & +0.10 & +2.90 & -0.70 & 4.7 \\
\hline & $\mu$ & +0.09 & +0.11 & +3.22 & -0.67 & +5.2 \\
\hline \multirow{2}{*}{ Angus $(\mathrm{N}=3)$} & $\bar{x}$ & +1.41 & +0.32 & +19.40 & +3.50 & +31.3 \\
\hline & $\mu$ & +0.68 & +0.06 & +19.30 & +5.40 & +20.7 \\
\hline \multirow{2}{*}{ Simmental $(N=3)$} & $\bar{x}$ & +1.50 & +1.06 & +18.00 & +13.30 & +25.0 \\
\hline & $\mu$ & +1.50 & +0.98 & +16.00 & +13.90 & +33.0 \\
\hline
\end{tabular}

\footnotetext{
${ }^{1} \bar{x}$ : average estimated breeding value (EBV) of sires used in this experiment, $\mu$ : overall breed average EBV
}

Management of the cattle was carried out according to the manual of the ARC for active participation in the National Beef Cattle Improvement Scheme. Strict cognizance was taken of contemporary group effects, especially the nutritional status of the various groups in the herd. Bulls received supplementary feeding prior to the breeding season to ensure that they reached a body score condition of 3.5 out of 5 before the mating season began. 
Dickerson $(1969,1973)$ presented general models for breed-specific genetic effects that explain variation among breed crosses. These models were first used in analyses of crossbreeding experiments and field data by Robison et al. (1981) and MacNeil et al. (1982), respectively. When partitioning the phenotypes of crossbred animals into these effects, it was assumed that there were no epistatic effects and no interactions among the effects. Thus, the model for a $F_{1}$ cross sired by breed $A$ and out of a breed $B$ dam can be written as follows:

$$
\mathrm{Px}(\mathrm{AB})=\frac{1}{2} g_{A}^{I}+\frac{1}{2} g_{B}^{I}+g_{B}^{M}+h_{A B}^{I}+e
$$

Where: $\mathrm{Px}(\mathrm{AB})=$ the phenotypic value of individual $\mathrm{X}$,

$g_{A}^{I}$ and $g_{B}^{I}=$ the individual additive effects of breeds A and B, respectively,

$g_{B}^{M}=$ maternal additive effect of the breed $B$ dam, which provides an environment for her offspring,

$h_{A B}^{I}=$ the individual heterosis effect which is expressed in AB crossbred progenies, and

$e=$ the temporal environmental effect to which the calf is subjected.

In a three-breed cross (e.g. sire breed $C$ mated to an $A B$ crossbred dam) the model can be extended to include an additional effect, namely the maternal heterosis effect $\left(h_{A B}^{M}\right)$, owing to the dam being a $\mathrm{F}_{1}$ cross. The model then becomes:

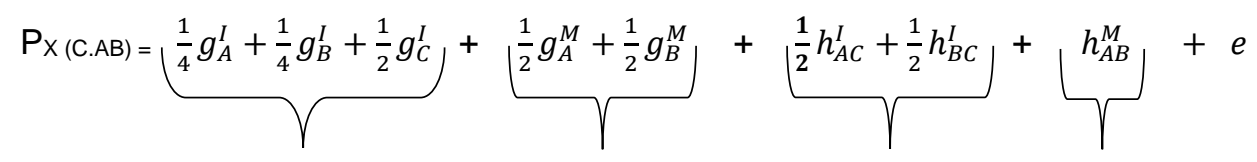

$$
\begin{array}{ccc}
\begin{array}{c}
\text { individual additive } \\
\text { effects }
\end{array} & \begin{array}{c}
\text { maternal additive } \\
\text { effects }
\end{array} & \begin{array}{c}
\text { individual and maternal } \\
\text { heterosis effects }
\end{array}
\end{array}
$$

The genetic effects were modelled with fixed continuous linear variates. The direct and maternal effects were expressed as deviations from the BN effect (i.e., $g_{B N}^{I}=g_{B N}^{M}=0$ ). Breed-specific heterosis effects were modelled as being proportional to expected heterozygosity. Heterosis in crosses with SM and AN was assumed to be equal to the average of the estimable heterosis effects. The genetic expectations for each breed group are presented in Table 3. The model also included random classification effects for herd of origin and dam that were assumed to be normally and independently distributed. All analyses were generated using PROC MIXED of the SAS ${ }^{\mathrm{TM}}$ System for Windows (version 8.2, SAS Institute Inc., Cary, NC, USA). For the preweaning traits, the model included fixed classification effects of year of birth of the calf, sex of calf and fixed linear and quadratic continuous effects of dam age at birth. A fixed linear continuous effect of weaning age was also included in the model for average daily gain from birth to weaning. The model for cow weight at weaning included fixed classification effects of year of weaning (completely confounded with year of birth of the calf), sex of calf and fixed linear and quadratic continuous effects of dam age at birth and a fixed linear continuous effect on age at which the calf was weaned. Breed effects were modelled with fixed continuous linear effects for the direct effects (equivalent to the maternal effects for pre-weaning traits). Again, random classification effects for herd of origin and dam were included in the model, each of which was assumed to be normally and independently distributed.

Breed direct and maternal additive effects and individual heterosis effects on birth weight, average daily gain from birth to weaning, weaning age and cow weight were estimated using multiple regression. To obtain a unique solution to the system of equations and estimate the effects, the constraints $g_{B N}^{i}=g_{B N}^{m}=0$ $\left(g_{B N}^{i}=\right.$ the individual additive effect of $\mathrm{BN}$ and $g_{B N}^{m}=$ the maternal additive effect of BN were imposed.

Following imposition of the constraints, the genetic effects portion of the model for an arbitrary phenotype $(y)$ is:

$$
y=G_{0}+b_{1} g_{A F}^{i}+b_{2} g_{N G}^{i}+b_{3} g_{A N}^{i}+b_{4} g_{S M}^{i}+b_{5} h_{A F x B N}^{i}+b_{6} h_{A F x N G}^{i}+b_{7} h_{B N x N G}^{i}+b_{8} g_{A F}^{m}+b_{9} g_{N G}^{m}
$$

Where: $G_{0}$ is the intercept which, given the constraints imposed, was equivalent to the predicted value for $\mathrm{BN} ; b_{1}$ to $b_{4}$ are the relative contributions of individual additive effects $\left(g^{i}\right)$ from AF, NG, AN, and SM, respectively;

$b_{5}$ to $b_{7}$ are proportions of heterosis $\left(h^{i}\right)$ arising from crosses of $\mathrm{AF}$ with $\mathrm{BN}, \mathrm{AF}$ with $\mathrm{NG}$, and $\mathrm{BN}$ with NG, respectively; and

$b_{8}$ and $b_{9}$ are the relative contributions of maternal additive effects $\left(g^{m}\right)$ from AF and $N G$, respectively. 
Table 3 Genetic expectations for breeds and breed crosses (breed of sire $x$ breed of dam) that were evaluated. Breed direct and maternal additive effects of $\mathrm{BN}$ were assumed to be 0

\begin{tabular}{|c|c|c|c|c|c|c|c|c|c|}
\hline \multirow{2}{*}{ Breed group } & \multicolumn{9}{|c|}{ Genetic effects $^{1}$} \\
\hline & $g_{A F}^{i}$ & $g_{N G}^{i}$ & $g_{A N}^{i}$ & $g_{S M}^{i}$ & $h_{A F \times B N}^{i}$ & $h_{A F \times N G}^{i}$ & $h_{B N \times N G}^{i}$ & $g_{A F}^{m}$ & $g_{N G}^{m}$ \\
\hline $\mathrm{AF}$ & 1.0 & & & & & & & 1.0 & \\
\hline$N G$ & & 1.0 & & & & & & & 1.0 \\
\hline $\mathrm{BN} \times \mathrm{AF}$ & 0.5 & & & & 1.0 & & & 1.0 & \\
\hline$A F \times B N$ & 0.5 & & & & 1.0 & & & & \\
\hline $\mathrm{BN} \times \mathrm{NG}$ & & 0.5 & & & & & 1.0 & & 1.0 \\
\hline$N G \times B N$ & & 0.5 & & & & & 1.0 & & \\
\hline$A F \times N G$ & 0.5 & 0.5 & & & & 1.0 & & & 1.0 \\
\hline$N G \times A F$ & 0.5 & 0.5 & & & & 1.0 & & 1.0 & \\
\hline $\mathrm{AN} \times \mathrm{AF}$ & 0.5 & & 0.5 & & $0.333 \ldots$ & $0.333 \ldots$ & $0.333 \ldots$ & 1.0 & \\
\hline$A N \times B N$ & & & 0.5 & & $0.333 \ldots$ & $0.333 \ldots$ & $0.333 \ldots$ & & \\
\hline$A N \times N G$ & & 0.5 & 0.5 & & $0.333 \ldots$ & $0.333 .$. & $0.333 .$. & & 1.0 \\
\hline $\mathrm{SM} \times \mathrm{AF}$ & 0.5 & & & 0.5 & $0.333 \ldots$ & $0.333 \ldots$ & $0.333 \ldots$ & 1.0 & \\
\hline$S M \times B N$ & & & & 0.5 & $0.333 \ldots$ & $0.333 \ldots$ & $0.333 \ldots$ & & \\
\hline$S M \times N G$ & & 0.5 & & 0.5 & $0.333 \ldots$ & $0.333 .$. & 0.333. & & 1.0 \\
\hline
\end{tabular}

AF: Afrikaner, AN: Angus, BN: Bonsmara, NG: Nguni, SM: Simmentaler

${ }^{1} g^{i}$ : individual additive effect of the subscripted breed, $\mathrm{h}^{\mathrm{i}}$ : individual heterosis effect attributable to the subscripted combination of breeds and $g^{m}$ : maternal additive effect of the subscripted breed

Predicted performance of the breed groups followed standard regression theory (Kinghorn, 1982). Prediction of merit of untested breed crosses is similar (MacNeil et al., 1988). For example, the equilibrium value of a given phenotype for the two-breed rotation of $\mathrm{BN}$ and $\mathrm{AF}\left(R_{A F X B N}\right)$ is given by:

$$
R_{A F x B N}=G_{0}+\frac{1}{2} g_{A F}^{i}+\frac{1}{2} g_{B N}^{i}+\frac{1}{2} g_{A F}^{m}+\frac{1}{2} g_{B N}^{m}+\frac{2}{3} h_{A F x B N}^{i}+\frac{2}{3} h_{A F x B N}^{m}
$$

Noticeably, maternal heterosis effects were not estimable from the data and in calculating these predicted values it was necessary to assume values for the contribution of maternal heterosis. Estimates from MacNeil et al. (1988) were used throughout. Given the constraints, the prediction of $R_{A F \times B N}$ reduces to:

$$
R_{A F x B N}=G_{0}+\frac{1}{2} g_{A F}^{i}+\frac{1}{2} g_{A F}^{m}+\frac{2}{3} h_{A F x B N}^{i}+\frac{2}{3} h_{A F x B N}^{m}
$$

Inter-generational variability is present in rotational crosses. For example, expectations for calves that result from mating breed AF sired females to bulls of breed $B N$ differ from those of calves that result from mating breed BN sired females to bulls of breed AF. Calves sired by bulls of breed BN from breed AF sired females have expectation equal to:

$$
G_{0}+\frac{1}{3} g_{A F}^{i}+\frac{2}{3} g_{B N}^{i}+\frac{2}{3} g_{A F}^{m}+\frac{1}{3} g_{B N}^{m}+\frac{2}{3} h_{A F x B N}^{i}+\frac{2}{3} h_{A F X B N}^{m}
$$

Conversely, calves sired by bulls of breed AF from breed BN sired females have the expectation of:

$$
G_{0}+\frac{2}{3} g_{A F}^{i}+\frac{1}{3} g_{B N}^{i}+\frac{1}{3} g_{A F}^{m}+\frac{2}{3} g_{B N}^{m}+\frac{2}{3} h_{A F \times B N}^{i}+\frac{2}{3} h_{A F \times B N}^{m}
$$

To quantify the inter-generational variability produced in two-breed rotational crossbreeding systems, 10000 animals representing each of the crosses were simulated using means predicted as described 
immediately above and the residual variances. Thereafter, the standard deviations for weaning weight and cow weight for the 20000 simulated animals were compared with the residual standard deviations.

Prediction of performance $(P)$ by top-cross calves sired by either AN or SM bulls out of two-breed rotational cross dams had the general form:

$$
P=G_{0}+\frac{1}{2} g_{T}^{i}+h^{i}+\frac{1}{2}\left[\frac{1}{2} g_{A F}^{i}+\frac{1}{2} g_{B N}^{i}+g_{A F}^{m}+g_{B N}^{m}\right]+\frac{2}{3} h_{A F \times B N}^{m}
$$

Where: $T$ designated the terminal sire breed, and

$h^{i}$ was the average individual heterosis effect. All other effects are as defined above.

\section{Results and Discussion}

Calves born earlier in the calving season grew more slowly $(1.28 \pm 0.21 \mathrm{~g} / \mathrm{d})$ from birth to weaning compared with those born later in the season $(P<0.05)$. Those cows that lactated for a longer period tended to weigh less $(23 \pm 12 \mathrm{~kg})$ at weaning than their contemporaries whose calves were born later in the season. Also across all breeds, male calves were heavier at birth (35.7 $\pm 0.4 \mathrm{vs}$. $34.6 \pm 0.4 \mathrm{~kg})$, grew more rapidly from birth to weaning ( $808 \pm 29$ vs. $753 \pm 28 \mathrm{~g} / \mathrm{d}$ ), and thus had greater 205-day weights (201. \pm 6 . vs. $189 . \pm$ $6 \mathrm{~kg}$ ) than their female contemporaries.

For all traits, the residual variance was by far the greatest identifiable sources of potential variability, indicating that there are other sources of variation beyond those explained by the model (Table 4). There was concern for potential heterogeneity of the variances among the herds of origin. However, at least given the small number of cows from any specific herd, such heterogeneity was not detected.

Table 4 Estimates of variance and percentage of total variance in brackets for random effects on preweaning traits and for cow weight at weaning

\begin{tabular}{lccccc}
\hline Component & Birth weight, kg & ADG, g/d & Weaning age, d & $\begin{array}{c}\text { 205-day weight, } \\
\text { kg }\end{array}$ & Cow weight, kg \\
\hline Dam & $0.00(0.0)$ & $1149(5.1)$ & $30(3.4)$ & $44(4.3)$ & $554(20.0)$ \\
Herd of origin within & $0.21(0.9)$ & $1328(5.9)$ & $39(4.4)$ & $52(5.1)$ & $149(5.4)$ \\
breed of dam & $23.44(99.1)$ & $20215(89.1)$ & $826(93.2)$ & $925(90.6)$ & $2069(74.6)$ \\
Residual & 23.65 & 22692 & 895 & 1021 & 2772 \\
Phenotypic & & & & & \\
\hline
\end{tabular}

For birth and 205-day weights, the estimates of residual variance were greater than estimates of phenotypic variance found by Meyer (1992) in summarizing within breed direct and maternal effects on growth traits of Australian beef cattle. Similarly, estimates of these variances were greater than the estimates of phenotypic variance found by Cantet et al. (1988) in analysing data from Hereford cattle. Thus, testing effects on these traits for significance may be compromised in the present study.

However, the residual variance for cow weight found here was marginally less than the corresponding phenotypic variance observed for mature weight in AN cattle (Kaps et al., 1999); and in the Germplasm Evaluation Program of USDA-ARS (Nephawe et al., 2004). This may be explained in part by cows from the present study weighing less than those studied by others and the general phenomena of variances tending to increase with means (Bartlett, 1947).

The breed-specific genetic effects that contributed to the performance of calves from this study are presented in Table 5. Estimates of the breed-specific direct effects on cow weight were $g_{N G}^{i}=-88.8 \pm 13.1$ and $g_{A F}^{i}=-8.1 \pm 15.7$. The maternal effect of the NG on birth weight and preweaning growth was less than that of the $\mathrm{BN}$ and, together with the negative effect on cow weight, indicated the potential for reduced feed intake on the part of the NG cows. In an earlier crossbreeding experiment, which was also conducted at Vaalharts Research Station, Theunissen et al. (2013) found the differences between AF and SM direct effects on birth weight and 205-day weight were $1.8 \pm 2.8$ and $27.3 \pm 12.9 \mathrm{~kg}$, respectively. The latter effect is substantially greater than the same effect estimated in the present study. Estimates of average individual heterosis effects on birth weight and 205-day weight from Theunissen et al. (2013) were 1.2 and $14.7 \mathrm{~kg}$, respectively, and again the effect on 205-day weight was greater than was observed here. There are multiple plausible explanations for the convergence of direct effects on birth and 205-day weights in the present 
study. First, and perhaps most likely, in the present study and in Theunissen (2013), which was based on Els (1988), the estimated breed effects reflect relatively small numbers of sires and thus the particular samples of sires may be divergent. Second, the genetic trends in the direct effects on the weights may have converged (Bergh et al., 2010) with this convergence masking any breed differences. Third, it is possible that these differences could be the result of interactions of genotype and environment. It should be noted that the 2015/2016 summer season was extremely hot and dry (Scholtz et al., 2016; South African Weather Service, 2016). During this hot and dry season it appeared that the AF and NG sired calves were less affected by the severe weather, relative to calves from the BN, AN and SM breeds of sire (Pyoos, 2019).

Given the general lack of significant $(P<0.05)$ effects in Table 5 , a post hoc power calculation was done using the numbers of straight-bred and reciprocal cross calves that contributed to the estimate of individual heterosis, and the observed residual standard deviation of 205-day weight. Given that heterosis for weaning is believed to be approximately $5 \%$ (Sacco, 1991), power-of-the-test was determined for a positive heterosis effect equal to $5 \%$ of the mean performance of the straight-bred calves. The resulting estimate of power was equal to 0.97 at $\alpha=0.05$. As described by Obeidat (2013), if heterosis is sufficiently elucidated by the dominance model, then crossbred animals are expected to express a fraction of the $\mathrm{F}_{1}$ heterosis that is proportional to the number of their heterozygous loci and such proportionality has been observed previously (e.g., Kress et al.,1992). However, while positive effects of heterosis were anticipated (Gregory et al., 1991), there is precedent for the inability to detect significant effects of heterosis on growth traits of beef cattle (Osorio-Arce and Segura-Correa, 2010).

Table 5 Breed direct and maternal additive, as deviations from Bonsmara, and individual heterosis effects on preweaning traits

\begin{tabular}{ccccc}
\hline Effect $^{1}$ & Birth weight, kg & ADG, g/day & Weaning age, day & 205-day weight, kg \\
\hline$g_{N G}^{i}$ & $-1.3 \pm 1.2$ & $-18 . \pm 36$. & $23.6 \pm 7.1^{\dagger}$ & $-5.1 \pm 7.6$ \\
$g_{A F}^{i}$ & $-1.9 \pm 1.6$ & $-26 . \pm 50$. & $5.4 \pm 10.0$ & $-7.2 \pm 10.7$ \\
$g_{S M}^{i}$ & $0.6 \pm 1.6$ & $-14 . \pm 49$. & $20.2 \pm 9.8^{\dagger}$ & $-3.0 \pm 10.5$ \\
$g_{A N}^{i}$ & $-2.1 \pm 1.6$ & $17 . \pm 49$. & $13.1 \pm 9.8$ & $0.5 \pm 10.4$ \\
$g_{N G}^{m}$ & $-3.1 \pm 1.0^{\dagger}$ & $-133 . \pm 42 .^{\dagger}$ & $-11.1 \pm 7.7$ & $-30.5 \pm 8.5^{\dagger}$ \\
$g_{A F}^{m}$ & $0.5 \pm 1.3$ & $-63 . \pm 53$. & $-2.6 \pm 9.9$ & $-12.3 \pm 10.9$ \\
$h_{A F \times B N}^{i}$ & $2.2 \pm 1.0^{\dagger}$ & $-25 . \pm 31$. & $0.0 \pm 6.1$ & $-2.7 \pm 6.5$ \\
$h_{A F \times N G}^{i}$ & $2.2 \pm 0.9^{\dagger}$ & $25 . \pm 27$. & $-1.3 \pm 5.4$ & $7.9 \pm 5.7$ \\
$h_{N G \times B N}^{i}$ & $0.7 \pm 0.6$ & $12 . \pm 20$. & $-3.4 \pm 3.9$ & $3.4 \pm 4.2$ \\
$h^{i}$ & $1.7 \pm 0.6^{\dagger}$ & $4 . \pm 18$. & $-1.6 \pm 3.6$ & $2.9 \pm 3.8$
\end{tabular}

${ }^{1} g_{N G}^{i}$ :breed direct effect of Nguni, $g_{A F}^{i}$ : breed direct effect of Afrikaner, $g_{S M}^{i}$ : breed direct effect of Simmentaler, $g_{A N}^{i}$ : breed direct effect of Angus, $g_{N G}^{m}$ : breed maternal effect of Nguni, $g_{A F}^{m}$ : breed maternal effect of Afrikaner, $h_{A F \times B N}^{i}$ : individual heterosis in crosses of Afrikaner and Bonsmara, $h_{A F \times N G}^{i}$ : individual heterosis in crosses of Afrikaner and Nguni, $h_{N G \times B N}^{i}$ : individual heterosis in crosses of Nguni and Bonsmara, and $h^{i}$ : average individual heterosis effect. $+P<0.05$

AF: Afrikaner, AN: Angus, BN: Bonsmara, NG: Nguni, SM: Simmentaler

Predicted means for purebred performance are presented in Table 6. At birth, NG calves weighed less compared with either BN or AF calves. The NG calves also grew more slowly from birth to weaning than BN calves. As a consequence of these effects, BM calves were heavier at weaning than either AF or NG calves. The calves from Nguni dams were older at weaning than those from BN dams (210 days versus 198 days). The reason for this is not clear, but it is speculated that the gestation length of the NG cow is shorter than that of the $\mathrm{BN}$ cow, which, for one of many reasons, could be due to breed frame size. That is, the uterine size of the NG cow is smaller. Another reason may be that NG cows express estrous earlier in the breeding season. For cow weight, the separation of the NG from AF and BM resulted from the corresponding differences in the breed direct effects. Means for birth weight and 205-day weight for AF in this study did not differ from the corresponding means observed by Theunissen et al. (2013). 
Table 6 Predicted means of straight-bred Bonsmara, Nguni and Afrikaner calves for preweaning traits and for weight at weaning of their dams at 7 years old

\begin{tabular}{lccccc}
\hline Breed & Birth weight, $\mathrm{kg}$ & ADG, g/d & Weaning age, $\mathrm{d}$ & 205-day weight, kg & Cow Weight, kg \\
\hline Bonsmara & $37.3 \pm 0.7$ & $884 \pm 62$ & $198 \pm 11$ & $218 \pm 13$ & $454 \pm 10$ \\
Nguni & $32.9 \pm 0.6$ & $742 \pm 31$ & $210 \pm 6$ & $185 \pm 6$ & $365 \pm 7$ \\
Afrikaner & $36.0 \pm 0.9$ & $763 \pm 31$ & $202 \pm 8$ & $192 \pm 9$ & $446 \pm 10$ \\
\hline
\end{tabular}

There were no significant differences among top-cross calves from $\mathrm{AF}$ and $\mathrm{BN}$ dams with regards to birth weight, average daily gain from birth to weaning, weaning age, and 205-day weight (Table 7). However, top-cross calves from NG dams had lighter birth weight, but generally did not differ from top-cross calves out of $\mathrm{BN}$ or $\mathrm{AF}$ dams in subsequent preweaning performance, confirming the results of Theunissen et al., (2013).

Table 7 Predicted mean performance for preweaning traits of top-cross calves sired by Afrikaner, Angus, Bonsmara, Nguni and Simmentaler bulls from Afrikaner, Bonsmara, and Nguni dams ${ }^{1}$

\begin{tabular}{lcccc}
\hline \multirow{2}{*}{ Trait } & \multicolumn{3}{c}{ Breed of dam } \\
\cline { 2 - 5 } Birth weight, kg & Breed of sire & AF & BN & NG \\
& AF & & $38.1 \pm 0.8$ & $34.3 \pm 0.7$ \\
& AN & $37.5 \pm 0.9$ & $38.0 \pm 0.7$ & $34.2 \pm 0.7$ \\
BN & $38.6 \pm 0.9$ & & $35.3 \pm 0.7$ \\
Average daily gain, g/d & NG & $37.9 \pm 1.0$ & $38.4 \pm 0.8$ & \\
& SM & $38.9 \pm 0.9$ & $39.3 \pm 0.8$ & $35.6 \pm 0.7$ \\
& AF & & $868 \pm 62$ & $741 \pm 34$ \\
WN & $812 \pm 72$ & $909 \pm 62$ & $782 \pm 32$ \\
Weaning age, d & BN & $794 \pm 72$ & & $765 \pm 34$ \\
& NG & $765 \pm 74$ & $876 \pm 63$ & \\
205-day weight, kg & SM & $746 \pm 73$ & $872 \pm 62$ & $746 \pm 33$ \\
& AF & & $201 \pm 11$ & $203 \pm 6$ \\
& AN & $205 \pm 8$ & $203 \pm 11$ & $205 \pm 6$ \\
BN & $199 \pm 9$ & & $200 \pm 6$ \\
& NG & $210 \pm 9$ & $208 \pm 11$ & \\
& SM & $209 \pm 8$ & $208 \pm 11$ & $210 \pm 6$ \\
Cow weight, kg & AF & & $216 \pm 13$ & $187 \pm 7$ \\
& AN & $204 \pm 9$ & $224 \pm 13$ & $195 \pm 7$ \\
& BN & $202 \pm 10$ & & $193 \pm 7$
\end{tabular}

\footnotetext{
${ }^{1}$ The individual heterosis effect on cow weight was not estimable from the experimental data and an estimate of $48 \mathrm{~kg}$ (Boenig, 2011) was used in predicting these means. Maternal effects on cow weight were assumed nil and thus there were no reciprocal differences

AF: Afrikaner, AN: Angus, BN: Bonsmara, NG: Nguni, SM: Simmentaler
} 
Generally, the performance of the calves sired by the various breeds of sire, was not different in this dataset. In interpreting these results, it is important to note the magnitude of the standard errors that are associated with the various means. These sizable estimates of within group variation may be indicative of either data quality or the scope of the experiment and raise caution against interpreting the lack of significant differences as indicating true biological similarity.

Differences among rational cross-mating systems were relatively small, irrespective of the breeds employed (Table 8). Because only straight-bred cows were present in the experiment, it was necessary to assume a value for individual heterosis for cow weight based on the literature. Here, a $47.9 \mathrm{~kg}$ increase in cow weight was assumed to result from individual heterosis (Boenig, 2011). The net result of these assumptions is potentially to change the individual breed group predicted values. However, the comparison of any two means is unaffected as the effects are constant increments in the prediction of breed group means based on the experimental data.

The Nguni-Afrikaner crisscross produced approximately $12 \mathrm{~kg}$ less weight at weaning relative to the other pairs of breed combinations. Further, the NG-sired generations of crisscross dams weighed the least at weaning. This may be expected as the NG breed has a smaller frame compared with others in this crossbreeding system (Scholtz, 2010). Taking residuals from the regression of breed group means for weaning weight on cow weight as a measure of efficiency indicated a range in efficiency of approximately 10 $\mathrm{kg}$. The NG-BN rotational system was most efficient and the NG-AF rotation was least efficient, with the BN$\mathrm{AF}$ rotation being of intermediate efficiency.

Table 8 Predicted performance for preweaning traits from calves produced using two-breed rotational crossbreeding systems and the predicted weights of their dams at 7 years old

\begin{tabular}{lcccccc}
\hline Breed of sire & Breed of dam & Birth weight, kg & ADG, g/d & Weaning age, d $\begin{array}{c}\text { 205-day weight, } \\
\mathrm{kg}\end{array}$ & Cow weight ${ }^{1}, \mathrm{~kg}$ \\
\hline $\mathrm{BN}$ & $2 / 3 \mathrm{AF}^{1} / 3 \mathrm{BN}$ & $38.5 \pm 0.9$ & $814 \pm 42$ & $200 \pm 8$ & $206 \pm 9$ & $481 \pm 8$ \\
$\mathrm{AF}$ & $2 / 3 \mathrm{BN}^{1} / 3 \mathrm{AF}$ & $37.7 \pm 0.8$ & $822 \pm 47$ & $202 \pm 9$ & $206 \pm 10$ & $483 \pm 9$ \\
$\mathrm{NG}$ & $2 / 3 \mathrm{AF}^{1 / 3} \mathrm{NG}$ & $36.6 \pm 0.9$ & $774 \pm 38$ & $210 \pm 7$ & $196 \pm 8$ & $451 \pm 7$ \\
$\mathrm{AF}$ & $2 / 3 \mathrm{NG}^{1} / 3 \mathrm{AF}$ & $35.2 \pm 0.6$ & $756 \pm 27$ & $203 \pm 5$ & $191 \pm 6$ & $424 \pm 6$ \\
$\mathrm{NG}$ & $2 / 3 \mathrm{BN}^{1} / 3 \mathrm{NG}$ & $35.8 \pm 0.6$ & $834 \pm 44$ & $207 \pm 8$ & $207 \pm 9$ & $456 \pm 9$ \\
$\mathrm{BN}$ & $2 / 3 \mathrm{NG}^{1} / 3 \mathrm{BN}$ & $35.3 \pm 0.6$ & $807 \pm 32$ & $197 \pm 6$ & $201 \pm 7$ & $427 \pm 7$
\end{tabular}

1The individual heterosis effect on cow weight was not estimable from the experimental data and an estimate of $48 \mathrm{~kg}$ (Boenig, 2011) was used in predicting these means

AF: Afrikaner, AN: Angus, BN: Bonsmara, NG: Nguni, SM: Simmentaler

In rotational crossbreeding systems, concern has been expressed that breeds differing greatly in mature weight and/or milk production might result in inter-generational differences in nutrient requirements (Marshall et al., 1990; Greiner, 2005). Because generations will overlap within a herd at any particular point in time, these inter-generational differences could create management difficulties due to increased variability among cows in their nutrient requirements. In these data, the inter-generational genetic differences in cow weight increased its standard deviation by 5 to $6 \%$ in rotational crossing systems that involved Nguni compared with straight-bred systems. Variability in cow weight was least affected by the inter-generational genetic differences in the two-breed rotation of $\mathrm{AF}$ and BN. For weaning weight, the increase in variability due to inter-generational genetic differences was negligible for all three rotational systems.

Expected performance of calves' sired by AN and SM bulls used as terminal sires on two-breed rotation females is presented in Table 9. These calves benefit from the full expression of individual heterosis compared with the straight-bred calves and to a lesser extent the calves from the crisscross systems. For traits expressed by the calf, but not those expressed by the dam, inter-generational variability is reduced in terminal sire systems.

Using the same residual metric described above as a measure of efficiency, the straight-bred system was least efficient, followed by the crisscross systems $(+2 \%)$ and the terminal sire system that utilized SM $(+4 \%)$, with the terminal sire system utilizing AN being on average most efficient $(+8 \%)$. The improved efficiency of the terminal sire systems, relative to the crisscross system results entirely from the increased weaning weight, because cow weight is unchanged. In the terminal sire system, crisscross females are used because $F_{1}$ females, which would express maximum heterosis, may be unavailable or expensive to 
purchase, while straight-bred females that are needed to produce $F_{1}$ females are expensive to maintain. Heterosis expression is generally assumed to be proportional to heterozygosity (Hill, 1982). Thus, in rotational crossing maximum heterosis is expressed in the $F_{1}$ generation, decreases in the next generation, and continues to move toward the expected equilibrium value in succeeding generations. However, there are occasional examples in which this relationship has not held true (Sheridan, 1981). In an extreme case, Australian research showed a total loss of heterosis for calving rate in the second generation $\left(\mathrm{F}_{2}\right)$ of inter se mating between Bos indicus and Bos taurus cows (Seifert \& Kennedy, 1972; Seebeck, 1973).

Table 9 Predicted performance for preweaning traits from calves produced using Angus and Simmentaler terminal sires on two-breed rotational crossbred females

\begin{tabular}{|c|c|c|c|c|c|}
\hline Breed of sire & Breed of dam & Birth weight, kg & $A D G, g / d$ & Weaning age, $d$ & $\begin{array}{c}\text { 205-day weight, } \\
\text { kg }\end{array}$ \\
\hline \multirow[t]{6}{*}{ Angus } & $2 / 3 \mathrm{AF}^{1} / 3 \mathrm{BN}$ & $38.0 \pm 0.8^{b}$ & $852 \pm 40^{b}$ & $203 \pm 7^{a}$ & $213 \pm 8^{b}$ \\
\hline & $2 / 3 \mathrm{BN} 1 / 3 \mathrm{AF}$ & $37.5 \pm 0.7^{a}$ & $869 \pm 46^{b}$ & $205 \pm 8^{\mathrm{a}}$ & $215 \pm 10^{b}$ \\
\hline & $2 / 3 \mathrm{AF}^{1 / 3} \mathrm{NG}$ & $37.6 \pm 0.9^{b}$ & $841 \pm 41^{a}$ & $210 \pm 8^{b}$ & $210 \pm 9^{a}$ \\
\hline & $2 / 3 \mathrm{NG}^{1} / 3 \mathrm{AF}$ & $37.4 \pm 0.8^{a}$ & $863 \pm 47^{b}$ & $208 \pm 9^{b}$ & $214 \pm 10^{b}$ \\
\hline & $2 / 3 \mathrm{BN} 1 / 3 \mathrm{NG}$ & $35.7 \pm 0.6^{a}$ & $830 \pm 33^{a}$ & $201 \pm 6^{a}$ & $206 \pm 7^{a}$ \\
\hline & $2 / 3 N^{1} 1 / 3 B N$ & $36.5 \pm 0.7^{a}$ & $862 \pm 45^{b}$ & $207 \pm 8^{b}$ & $213 \pm 9^{b}$ \\
\hline \multirow[t]{6}{*}{ Simmentaler } & $2 / 3 \mathrm{AF}^{1} / 3 \mathrm{BN}$ & $39.4 \pm 0.8^{b}$ & $816 \pm 40^{a}$ & $208 \pm 7^{a}$ & $207 \pm 8^{\mathrm{a}}$ \\
\hline & $2 / 3 \mathrm{BN} 1 / 3 \mathrm{AF}$ & $38.9 \pm 0.7^{b}$ & $832 \pm 46^{b}$ & $209 \pm 8^{\mathrm{a}}$ & $209 \pm 10^{b}$ \\
\hline & $2 / 3 \mathrm{AF}^{-1 / 3} \mathrm{NG}$ & $38.9 \pm 0.9^{b}$ & $805 \pm 42^{a}$ & $214 \pm 8^{b}$ & $204 \pm 9^{a}$ \\
\hline & $2 / 3 \mathrm{NG}^{1} / 3 \mathrm{AF}$ & $38.7 \pm 0.8^{b}$ & $827 \pm 47^{b}$ & $212 \pm 9^{b}$ & $208 \pm 10^{b}$ \\
\hline & $2 / 3 \mathrm{BN} 1 / 3 \mathrm{NG}$ & $37.0 \pm 0.7^{a}$ & $794 \pm 34^{c}$ & $206 \pm 6^{a}$ & $200 \pm 7^{a}$ \\
\hline & $2 / 3 N^{1} 1 / 3 B N$ & $37.9 \pm 0.7^{a}$ & $825 \pm 46^{b}$ & $212 \pm 8^{b}$ & $208 \pm 10^{\mathrm{b}}$ \\
\hline
\end{tabular}

a, b, c Within a column, means with a common superscript do not differ at $P=0.05$

AF: Afrikaner, AN: Angus, BN: Bonsmara, NG: Nguni, SM: Simmentaler

\section{Conclusion}

The results presented here demonstrate the utility of estimating breed effects by multiple regression in order to facilitate examination of untested breed groups and crossbreeding systems. An experimental examination of crossbreeding systems taken to equilibrium breed composition and stabilized heterosis would require a much longer (and costlier) experiment compared with the three years of investigation presented here. Despite the relatively small magnitude of the observed genetic effects, advantages of crossbreeding systems that capture substantial portions of the heterosis effects were evident.

\section{Acknowledgements}

Acknowledgements are extended to Animal Breeding \& Genetics, ARC-AP staff members. Thanks are extended to the Vaalharts Research Station in Kimberley, Northern Cape Department of Agriculture, Land Reform and Rural Development, particularly to O. Ntwaeagae and W. Peterson for collecting the data and looking after the cattle. This study was supported financially by Red Meat Research and Development South Africa (RMRD-SA) and Technology and Human Resources for Industry Programme (THRIP) through the National Research Foundation (NRF).

\section{Authors' Contributions}

This study comprised the MSc research of GMP. MMS, FWCN, and MDM conceived the investigation. AT supervised the research at Vaalharts Research Station and made the data available. GMP prepared the data for analysis and analysed them with MDM. All authors contributed to interpretation of the results. GMP drafted the initial manuscript, which was subsequently edited by MMS, FWCN, and MDM. All authors read and approved the final manuscript.

\section{Conflict of Interest Declaration}

The authors declare that they have no conflicts of interest with regard to this work.

\section{References}

Acocks, J.P.H., 1988. Veld types of South Africa. 3. Memoirs of the Botanical Survey of South Africa No. 57. Witwatersrand Botanical Garden, National Botanical Institute, Johannesburg, South Africa. 
Amen, T.S., Herring, A.D., Sanders J.O. \& Gill, C.A., 2007. Evaluation of reciprocal differences in Bos indicus $\times$ Bos taurus backcross calves produced through embryo transfer: I. Birth and weaning traits. J. Anim. Sci. 85, 365-372. doi:10.2527/jas.2005-754.

Arce, R.O.N., 2006. Evaluation of heterosis and heterosis retention in bos-taurus bos indicus crossbred cattle for reproductive and maternal traits in cows. M.Sc. thesis, Texas A\&M University, College Station. USA.

Bartlett, M.S., 1947. The use of transformations. Biometrics 3, 39-52.

Bergh, L., Gerhard, R., Scholtz, M.M. \& Mamabolo, M.J., 2010. Introduction to the information on beef and dual purpose breeds in South Africa. In: M.M. Scholtz (editor). Beef breeding in South Africa. Agricultural Research Council, Pretoria, South Africa.

Boenig, L., 2011. Heterosis and heterosis retention for reproductive and maternal traits in Brahman $\mathrm{x}$ Hereford crossbred cows. MS thesis, Texas A\&M University, College Station.

Bradley, D.G. \& Cunningham, P., 1999. Genetic aspects of domestication, common breeds and their origins. In: R. Fries and $A$. Ruvinsky (eds). The genetics of cattle. CAB International, Wallingford, United Kingdom.

Bunning, H., Wall, E., Chagunda, M.G.G., Banos, G. \& Simm, G., 2019. Heterosis in cattle crossbreeding schemes in tropical regions: meta-analysis of effects of breed combination, trait type, and climate on level of heterosis. J. Anim. Sci. 97(1), 29-34.

Cantet, R.J.C., Kress, D.D., Anderson, D.C., Doornbos, D.E., Burfening P.J. \& Blackwell, R.L., 1988. Direct and maternal variances and covariances and maternal phenotypic effects on preweaning growth of beef cattle. J. Anim. Sci. 66 , $648-660$.

Cardoso, F.F. \& Templeman, R.J., 2004. The value of hierarchical Bayes models on genetic evaluation of multiple-breed beef cattle populations. J. Anim. Sci. 83, 62-72.

Cartwright, T.C., Ellis, G.F., Jr., Kruse, W.E. \& Crouch, E.K., 1964. Hybrid vigor in Brahman Hereford crosses. Texas Agr. Exp. Sta. Tech. Monogr. I.

Cunningham, E.P., 1987. Crossbreeding-The Greek temple model. J. Anim. Breed. Genet. 104, 2-11.

Dickerson, G.E., 1969. Experimental approaches to utilizing breed resources. Animal Breeding Abstracts 37, $191-202$.

Dickerson, G.E., 1973. Inbreeding and heterosis in animals. Proc. Anim. Breed. Genet. Symposium in honour of Dr. J.L. Lush, ASAS, ADSA. Pp. 54-77.

Dillard, E.U., Rodriguez, O. \& Robison, O.W., 1980. Estimation of additive and non-additive direct and maternal genetic effects from crossbreeding beef cattle. J. Anim. Sci. 50, 653-663.

Els, D.L., 1988. Kruisteling vir vleisproduksie. PhD thesis, University of the Free State. Bloemfontain, South Africa.

Epstein, H., 1971. The origin of domestic animals in Africa. Vol. 1. New York, Africana.

Eriksson, S., Ask-Gullstrand, P., Fikse, W.F., Jonsson, E., Eriksson, J., Stålhammar, H. Wallenbeck, A. \& Hessle, A., 2020. Different beef breed sires used for crossbreeding with Swedish dairy cows - effects on calving performance and carcass traits. Lvstk. Sci. 232, 103902. https://doi.org/10.1016/j.livsci.2019.103902

Frisch, J.E., 1973. Comparative drought resistance of Bos indicus and Bos taurus crossbreds in central Queensland 2. Relative mortality rates, calf weights and weight changes of breeding cows. Aust. J. Exp. Anim. Husb. 13, 117133.

Gregory, K.E., Cundiff, L.V. \& Koch, R.M., 1991. Breed effects and heterosis in advanced generations of composite populations for preweaning traits of beef cattle. J. Anim. Sci. 69, 947-960.

Gregory, K.E., Swiger, L.A., Koch, R.M., Sumption, L.J., Rowden W.W. \& Ingalls, J.E., 1965. Heterosis in preweaning traits of beef cattle. J. Anita. Sci. 24, 21.

Greiner, S.P., 2005. Crossbreeding beef cattle. Virginia Cooperative Extension Publ. 800-405. Blacksburg.

Griffing, B. \& Zsiros, E., 1971. Heterosis associated with genotype-environment interactions. Genetics 68, 443-455.

Haldane, J.B.S., 1946. The interaction of nature and nurture. Ann. Eugenics, 13, 197-205.

Hanotte, O., Bradley, D.G., Ochieng, J.W., Verjee, Y., Hill, E.W. \& Rege, J.E.O., 2002. African pastoralism: Genetic imprints of origins and migrations. Science 296, 336-9.

Hedrick, H.B., Lasley, J.F., Jain, J.P., Krause, G.F., Sibbit, B., Langford, L., Comfort, J.E. \& Dwyer A.J., 1970. Quantitative carcass characteristics of reciprocally crossed Angus, Charolais and Hereford heifers. J. Anita. Sci. 31, 633.

Herman, P.P.J., 2002. Revision of the Tarchonanthus camphoratus complex (AsteraceaeTarchonantheae) in southern Africa. Bothalia 32, 21-28.

Hill, W.G., 1982. Dominance and epistasis as components of heterosis. J. Anim. Breed. Genet. 99, 161-168.

Kaps, M., Herring, W.O. \& Lamberson, W.R., 1999. Genetic and environmental parameters for mature weight in Angus cattle. J. Anim. Sci. 77, 569-574.

Kinghorn, B.P., 1980. A model for the optimization of genetic improvement by the introduction of novel breeds into a native population. Z Tierz Züchtungsbiol 97, 95-100.

Kinghorn, B.P., 1982. Genetic effects in crossbreeding. II. Multibreed selection indices. Z. Tierz. Züchtungsbiol. 99, 315320.

Kress, D.D., Doornbos, D.E., Anderson, D.C. \& Rossi, D., 1992. Performance of crosses among Hereford, Angus and Simmental cattle with different levels of Simmental breeding. VI. Maternal heterosis of 3- to 8-year-old dams and the dominance model. J. Anim. Sci. 70, 7682-7687.

Long, C.R., 1980. Crossbreeding for beef production: Experimental results. J. Anim. Sci. 51, 1197-1223.

MacNeil. M.D., 1987. Formation of optimal composite populations. Theor. Appl. Genet. 74, 837-840.

MacNeil, M.D. \& Matjuda, L.E., 2007. Breeding objectives for Angus and Charolais specialized sire lines for use in the emerging sector of South African beef production. S. Afr. J. Anim. Sci. 37, 1-7. 
MacNeil, M.D., Cundiff, L.V. \& Gregory, K.E., 1988. Crossbreeding systems for beef production. Appl. Agri. Res. 3, 4454.

MacNeil, M.D., Dinkel, C.A. \& VanVleck, L.D., 1982. Individual and maternal additive and heterotic effects on 205-day weight in beef cattle. J. Anim. Sci. 54, 951-956.

Makina, S.O., Whitacre, L.K., Decker, J.E., Taylor, J.F., MacNeil, M.D., Scholtz, M.M., van Marle-Köster, E., Muchadeyi, F.C., Makgahlela, M.L. \& Maiwashe, A., 2016. Insight into the genetic composition of South African Sanga cattle using SNP data from cattle breeds worldwide. Genet. Sel. Evol. 48, 88. DOI:10.1186/s12711-016-0266-1

Marshall, D.M., Monfore, M.D. \& Dinkel, C.A., 1990. Performance of Hereford and two-breed rotational crosses of Hereford with Angus and Simmental cattle: I. Calf production through weaning. J. Anim. Sci. 68, 4051-4059.

Mendonça, F.S., MacNeil, M.D., Leal, W.S., Azambuja, R.C.C., Rodrigues, P.F. \& Cardoso, F.F., 2019. Crossbreeding effects on growth and efficiency in beef cow-calf systems: evaluation of Angus, Caracu, Hereford and Nelore breed direct, maternal and heterosis effects. Trans. Anim. Sci. 3, 1286-1295. https://doi.org/10.1093/tas/txz096

Meyer, K., 1992. Variance components due to direct and maternal effects for growth traits of Australian beef cattle. Livestock Prod. Sci. 31, 179-204

Nephawe, K.A., Cundiff, L.V., Dikeman, M.E., Crouse, J.D. \& Van Vleck, L.D., 2004. Genetic relationships between sexspecific traits in beef cattle: Mature weight, weight adjusted for body condition score, height and body condition score of cows, and carcass traits of their steer relatives. J. Anim. Sci. 82, 647-653.

Obeidat, M.D.T.H., 2013. Heterosis and heterosis retention for reproductive and maternal traits in Nellore-Angus crossbred cows. Doctorate dissertation, Texas A\&M University. Texas. USA. 10-13.

Osorio-Arce, M.M. \& Segura-Correa, J.C., 2010. Estimates of breed direct, maternal and heterosis effects for weaning and yearling weights of beef cattle in the humid tropics of Mexico. Trop. and Subtrop. Agro Eco. 12, 463-469.

Pollak, E.J., 2006. Multibreed genetic evaluations of beef cattle in the United States. 8th World Congress on Genetics Applied to Livestock Production, Belo Horizonte, MG, Brazil.

Pyoos, G.M., 2019. Crossbreeding effects on cow efficiency and component traits. MSc thesis, University of the Free State, Bloemfontain, South Africa.

Ramsay, K.A., 1985. The Nguni and its future in Southern Africa. Annual Nguni Production Sale, Bartlow Combine, KwaZulu-Natal, 12 Sept. (Lecture)

Robison, O.W., McDaniel, B.T. \& Rincon, E.J., 1981. Estimation of direct and maternal additive and heterotic effects from crossbreeding experiments in animals. J. Anim. Sci. 52, 44-50.

Seebeck, R.M., 1973. Sources of variation in the fertility of a herd of Zebu, British, and Zebu x British cattle in Northern Australia. J. Agric. Sci., U. K. 81, 253-262.

Seifert, G.W. \& Kennedy, J.F., 1972. A comparison of British breed crosses with F1 and F2 Zebu x British cattle on the basis of a productivity index. Proc. Aust. Soc. Anim. Prod. 9, 143-146.

Scholtz, M.M., 2010. Beef breeding in South Africa. 2nd edition. Irene, South Africa: Agricultural Research Council Animal Production Institute.

Scholtz, M.M., Maiwashe, A., Magadlela, M.A., Tjelele, T.J., Nkosi, B.D. \& Matabane, M., 2016. The reality of drought, consequences and mitigation strategies for livestock production in South Africa. Appl. Anim. Husb. Rural Dev. 9, 6-10.

Scholtz, M.M., Pyoos, G.M, Seshoka, M.M. \& Theunissen, A., 2018. The effect of climate on the pre- and post-weaning performance of different beef cattle genotypes. 12th World Cong. Anim. Prod., 5-8 July, Vancouver, Canada.

Sheridan, A.K., 1981. Crossbreeding and heterosis. Anim. Breed. Abstr. 49, 131-144.

South African Weather Service, 2016. General information South Africa - annual total rainfall. Public Document CLS-CIINFO-110.1

Spangler, M.L., 2007. The value of heterosis in cow herd: lessons from the past that apply to today. Range Beef Cow Symposium, University of Nebraska, Lincoln. https://digitalcommons.unl.edu/rangebeefcowsymp/21

Theunissen, A., Scholtz, M.M., Neser, F.W.C. \& MacNeil, M.D., 2013. Crossbreeding to increase beef production: Additive and non-additive effects on weight traits. S. Afr. J. Anim. Sci. 43, 143-152.

Willham, R.L., 1974. Beef-dairy crossbreeding. Proceedings of Working Symposium on Breed Evaluation and Crossing Experiments. Zeist, The Netherlands. 